\title{
PENGENALAN LAPORAN KEUANGAN NIRLABA PADA KOMUNITAS ARIMBIN IX
}

\author{
Anum Nuryani ${ }^{1}$, Dodi Persada ${ }^{2}$, Yusni Nuryani ${ }^{3}$, Ade Yusuf ${ }^{4}$, \\ Asep Muhammad Lutfi ${ }^{5}$ \\ Universitas Pamulang \\ dosen02517@unpam.ac.id
}

\begin{abstract}
Community service aims to introduce the financial statements of non-profit organizations. Arimbin IX is a non-profit organization in South Tangerang whose main activity is hiking. This community service method includes the observation stage, preparing stage, and implementation stage. The Implementation stage devided become to stages are explanation stages and training in making financial reports. Money is a sensitive thing for everyone, especially for an organization. In the organization it takes the finance department or treasurer to manage money. For reporting of income and expenditure of funds, men who are placed in the finance division must make financial reports. The Arimbin IX community has a treasurer, but seeing the educational background and age of all of its members makes us interested in carrying out this community service activity. In this activity we introduce accounting, the accounting cycle, entries, ledgers and financial reports including balance sheets, cash flow, activity reports and notes to financial statements. The result of this activity is that the organization has a financial division framework capable of producing accurate and reliable financial reports.
\end{abstract}

Keywords: Arimbin IX, Financial Statement, Organisasi Nirlaba

\begin{abstract}
Abstrak
Pengabdian kepada masyarakat bertujuan untuk memperkenalkan laporan keuangan organisasi nirlaba. Arimbin IX adalah organisasi nirlaba di Tangerang Selatan yang kegiatan utamanya adalah mendaki. Metode pengabdian masyarakat ini meliputi tahap observasi, tahap persiapan dan tahap pelaksanaan. Tahap pelaksanaan dibagi menjadi dua yakni penjelasan materi dan pelatihan pembuatan laporan keuangan. Uang adalah hal yang sensitif bagi setiap orang, terutama bagi sebuah organisasi. Dalam organisasi dibutuhkan bagian keuangan atau bendahara untuk mengelola uang. Untuk pelaporan pendapatan dan pengeluaran dana, pria yang ditempatkan di divisi keuangan harus membuat laporan keuangan. Komunitas Arimbin IX memiliki seorang bendahara, namun melihat latar belakang pendidikan dan usia semua anggotanya membuat kami tertarik untuk melakukan kegiatan pengabdian kepada masyarakat ini. Dalam kegiatan ini kami memperkenalkan akuntansi, siklus akuntansi, entri, buku besar dan laporan keuangan termasuk neraca, arus kas, laporan aktivitas dan
\end{abstract}


catatan atas laporan keuangan. Hasil dari kegiatan tersebut adalah organisasi memiliki kerangka divisi keuangan yang mampu menghasilkan laporan keuangan yang akurat dan andal.

Kata Kunci: Arimbin IX, Laporan keuangan, Organisasi Nirlaba

\section{A. PENDAhULUAN}

Seperti yang sudah kita ketahui bahwa organisasi terbagi menjadi dua yakni organisasi profit dan non profit. Organisasi profit berorientasikan pada keuntungan sehingga yang menajdi aktivitas utamanya yakni bisnis. Sedangkan Organisasi non-profit tidak berorientasikan pada keuntungan dan aktivitasnya berbeda-beda bergantung pada bidangnya masing-masing seperti pendidikan, keagamaan, kesehatan, kegemaran dan sejenisnya. Organisasi non-profit juga sering disebut dengan organisasi nirlaba.

Arimbin IX merupakan salah satu komunitas yang dapat dikategorikan organisasi nirlaba. Komunitas Arimbin IX merupakan komunitas pecinta alam. Komunitas Arimbin IX awalnya terbentuk dari ketidaksengajaan pemuda-pemuda parkiran. Karena memiliki kesamaan akhirnya terbentuklah komunitas Arimbin IX. Sampai Saat ini Komunitas Arimbin IX beranggotakan 25 orang. Anggotanya terdiri dari anggota senior dan junior. Anggota junior berusia maksimal 25 tahun artinya masih di bawah usia produktif.

Dalam suatu orgnaisasi terdapat sekumpulan orang yang saling bekerja sama melalui struktur saling berkoordinasi untuk mencapai tujuan organisasi. Pembina komunitas Arimbin IX menyampaikan bahwa komunitas telah mengalami regenerisasi yakni penyerahan jabatan dari senior kepada junior-junior selaku anggota yang diberikan kepercayaan untuk aktif dalam komunitas tersebut. Berdasarkan hasil observasi di lapangan ditemukan adanya variasi latar belakang anggota komunitas. Pendidikan dan usia yang belum masuk usia produktif menjadi pertimbangan adanya kegiatan pelatihan baik untuk kepemimpinan maupun untuk pengetahuan lainnya dalam berorganisasi seperti pelaporan keuangan.

Suatu organisasi tentunya memeiliki bagian keuangan atau bendahara untuk mengelola dana yang masuk maupun yang keluar. Seperti yang kita ketahui bahwa uang adalah hal yang sensitif sehingga perlu dilakukan pencatatan atau pembukuannya agar pergerakannya dapat dilaporkan secara transaparan dan dapat dipercaya oleh setiap anggota.

Menurut Sujarweni, (2015: 185) bahwa organisasi nirlaba memperoleh sumber dana dari sumbangan para anggota dan para penyumbang lain yang tidak mengharapkan imbalan apapun dari organisasi tersebut. Meskipun organisasi nirlaba tidak berorientasikan pada laba atau profit, organisasi nirlaba juga memerlukan laporan keuangan dalam aktivitasnya. Pencatatan pemasukan dan pengeluaran kas menjadi hal penting bagi organsiasi agar bisa mereview perolehan dan penggunaan anggaran secara optimal dalam aktivitas-aktivitas organisasi. Dalam Pernyataan Standar Akuntansi Keuangan (PSAK) No. 45 tahun 2011 tentang Pelaporan Keuangan organisasi nirlaba, laporan keuangan entitas nirlaba terdiri dari laporan posisi keuangan, laporan aktivitas, laporan arus kas, dan catatan atas laporan keuangan (Pontoh, 2013:3 dalam Anggraeny dkk).

Permasalahan dalam komunitas secara umum meliputi kebutuhan organisasi untuk menjalankan aktivitas nya melalui pembentukan kader dan anggota yang memiliki kemampuan dibidangnya termasuk bagian keuangan. Hai ini didasarkan karena latar belakang pendidikan yang bukan dari keuangan dan usia anggota komunitas tersebut.

Dengan adanya kegiatan pengabdian ini dapat membantu terbentuknya kader yang andal untuk bagian keuangan di Komunitas Arimbin IX. Sehingga perolehan dan penggunaan dana komunitas bisa dipertanggung jawabkan secara transparan dan andal. 


\section{B. METODE PELAKSANAAN KEGIATAN}

Pengabdian kepada masyarakat ini diaakan selama dua hari pada tanggal 07 - 08 November 2020. Acara diadakan di Jl. H. Som Rt 05/ Rw 01 Kelurahan Pondok Pucung Kecamatan Pondok Aren Tangerang Selatan - Banten. Sasarannya yakni seluruh anggota komunitas Arimbin IX termasuk anggota senior sebagai pembina dan anggota junior. Adapun metode dalam pelaksanaan kegiatan pengabdian ini meliputi:

\section{Tahap Observasi}

Meruapakan tahap awal kegiatan dengan tujuan agar mampu mengambrakan kondisi komunitas Arimbin IX yang dilakukan secara langsung bertemu dengan pembina komunitas yakni Bapak Imbron.

2. Tahap Persiapan

Meruapakan tahapan dalam mempersiapkan kegiatan pengabdian melalui sosialisasi adanya acra dan mempersiapkan waktu dan tempat pelaksanaan.

3. Tahap Pelaksanaan

a. Penjelasan Materi

Tahap ini diadakan pertemuan langsung dengan para anggota memberikan penjelasana materi mengenai akuntansi, sisklus akuntansi, jurnal, buku besar dan laporan keuangan.

b. Pelatihan Pembuatan Laporan Keuangan

Dalam tahap ini merupakan simulasi pembuatan laporan keuangan.

\section{HASIL DAN PEMBAHASAN}

1. Tahap Observasi

Observasi dilakukan sebanyak dua kali. Kali pertama dilakukan pertemuan dengan pembina untuk mengetahui kondisi komunitas Arimbin IX karena adanya proses regenerasi. Dalam pembina menjelaskan awalnya ada komunitas, anggota-anggotanya hingga kebutuhan SDM dalam penempatan posisi jabatan dalam komunitas termasuk bagian keuangan. Kunjungan kedua diadakan pertemuan dengan anggota komunitas. Dalam kunjungan terseut, diadakan wawancara dan sedikit mereview gamabran anggota sejauh mana mengetahui pembukuan. Dari kunjungan ini, para tim pengabdi mendapatkan informasi terkait materi yang dibutuhkan oleh anggota khususnya bagian keuangan atau bendahra komunitas.

2. Tahap Persiapan

Setelah melakukan observasi dilakukan tahap persiapan yang dilakukan pada bulan Oktober minggi terakhir. Tahap ini dilakukan sebanyak dua kali. Pertama pada menentukan waktu dan tempat pelaksanaan untuk kegiatan masyarakat. Tahap kedua dilakukan dengan pemberian surat pengantar kepada tokoh masyarakat dan pembina komunitas sehingga dapat menyampaikan tujuan dari kegiatan yang akan dilaksanakan.

3. Tahap Pelaksanaan

Pelaksanaan kegiatan pengabdian kepada masyarakat diadakan selama dua hari dari tanggal 7-8 November 2020. Dalam sekali pertemuan dilakukan selama 2 jam. Hari pertama yakni diberikannya penjelasan terkait materi yang mana diberikan judul "Pengenalan Laporan Keuangan Nirlaba pada Komunitas Arimbin IX". Pada hari kedua diadakan pelatihan pembuatan laporan keuangan.

a. Penjelasan Materi 
Penjelasana materi diadakan di Hari Sabtu tanggal 7 November 2020. Dalam tahap ini dihadiri oleh seluruh anggota komunitas Arimbin IX sebanyak 25 Orang. Materi yang disampaikan meliputi pemahmaan akuntansi, siklus akuntasi, jurnal, buku besar dan laporan keuangan. Materi tersebut disampaikan oleh Ibu Anum Nuryani, S.E., M.M., dan Ibu Yusni Nuryani, S.E., M.M. Kemudian sesi diskusi dan tanya jawab didampingi oleh Bapak Ade Yusuf, S.E., M.M.

Pada sesi tanya jawab salah satu yang menjadi pertanyaan oleh Bapak Abilah menanyakan bagaimana agar keuangan ini tidak menjadi hal yang tidak transparan bagi setiap anggota komunitas.

Tentu saja dengan adanya proses pencatatan keuangan akan menjadi awal proses laporan keuangan sehingga dapat dikonsumsi oleh semua anggota komunitas bahkan jika diperlukan pihak berkepentinganpun bisa mendapatkan informasi keuangannya. Proses pencatatan dilakukan secara rutin dan tidak dtunda-tunda dengan melakukan posting setiap waktu sesuai dengan hasil rapat dan kesepakatan setiap anggota agar terjadinya penyampaian informasi yang transparan dan andal.

b. Pelatihan Pembuatan Laporan Keuangan

Pada hari kedua dilakukan dengan pelatihan pembuatan laporan keuangan. Pelatihan pembuatan laporan keuangan didampingi oleh Pak Asep Muhammad Lutfi S.E., M.M., dan Bapak Dodi Persada S.E., M.M. Dalam tahap ini anggota dilatih membuat laporan keuangan seperti Posisi Keuangan, Laporan Aktivitas, Arus Kas dan Catatan atas laporan Keuangan.

Berikut contoh laporan keuangan yakni Laporan Posisi Keuangan (Neraca) yang dibuat:

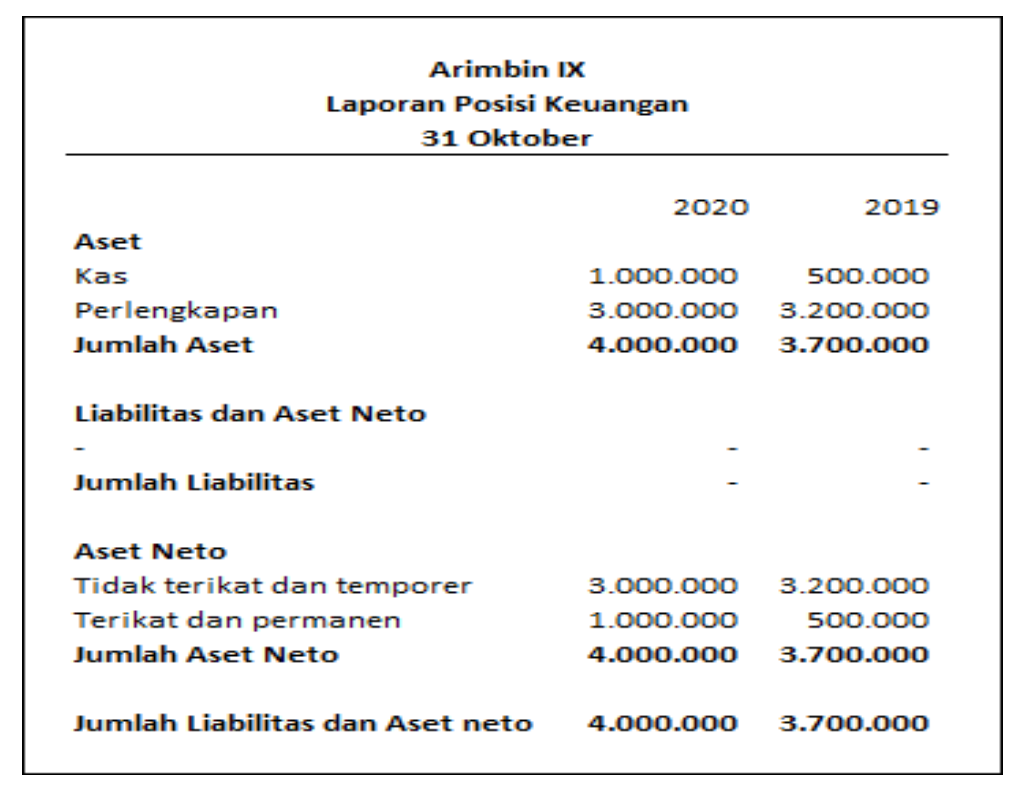

\section{Gambar 1 Hasil Simulasi Laporan Posisi Keuangan Komunitas Arimbin IX}

Secara singkat susunan acara kegiatan pelaksanaan pengabdian kepada masyarakat ini ditunjukan oleah tabel berikut: 
Vol. 2, No. 1, Januari 2021, Hal (107-112)

@Prodi Manajemen Fakultas Ekonomi Universitas Pamulang

Tabel 1 Susunan Acara Pelaksanaan

\begin{tabular}{|c|c|c|c|}
\hline Tanggal & Jam & Susunan Acara & PIC \\
\hline \multirow{8}{*}{$\begin{array}{c}7 \\
\text { November } \\
2020\end{array}$} & $19: 15-19: 30$ & Persiapan dan Pembukaan & $\begin{array}{l}\text { Bapak Dodi Persada, S.E., } \\
\text { M.M. }\end{array}$ \\
\hline & $19: 30-19: 45$ & Sambutan Ketua Pengabdian & $\begin{array}{l}\text { Ibu Anum Nuryani, S.E., } \\
\text { M.M. }\end{array}$ \\
\hline & $19: 45-20: 00$ & Sambutan Tokoh Masyarakat & Bapak Jumadi \\
\hline & $20: 00-20: 15$ & $\begin{array}{l}\text { Sambutan Ketua Komunitas } \\
\text { Arimbin IX }\end{array}$ & Bapa Rizky Pramudiyah \\
\hline & $20: 15-21: 15$ & Penjelasan Materi & $\begin{array}{l}\text { Ibu Yusni Nuryani, S.E., } \\
\text { M.M. Dan Ibu Anum } \\
\text { Nuryani S.E., M.M. }\end{array}$ \\
\hline & $21: 15-21: 30$ & Ice Breaking & $\begin{array}{l}\text { Bapak Ade Yusuf, S.E., } \\
\text { M.M. }\end{array}$ \\
\hline & $21: 30-22: 00$ & Diskusi dan Tanya Jawab & $\begin{array}{l}\text { Bapak Ade Yusuf, S.E., } \\
\text { M.M. }\end{array}$ \\
\hline & $22: 00-22: 15$ & Kesimpulan dan sosialisasi sesi 2 & $\begin{array}{l}\text { Bapak Asep Muhammad } \\
\text { Lutfi, S.E., M.M. }\end{array}$ \\
\hline \multirow{4}{*}{$\begin{array}{c}8 \\
\text { November } \\
2020\end{array}$} & $19: 30-19: 45$ & Pembukaan & $\begin{array}{l}\text { Ibu Anum Nuryani, S.E., } \\
\text { M.M. }\end{array}$ \\
\hline & $19: 45-20: 15$ & $\begin{array}{l}\text { Review Materi yang sudah } \\
\text { disampaikan }\end{array}$ & $\begin{array}{l}\text { Ibu yusni Nuryani, S.E., } \\
\text { M.M. }\end{array}$ \\
\hline & $20: 15-21: 15$ & $\begin{array}{l}\text { Simulasi Pembuatan Laporan } \\
\text { Keuangan }\end{array}$ & $\begin{array}{l}\text { Bapak Asep Muhammad } \\
\text { Lutfi, S.E., M.M. Dan } \\
\text { Bapak Dodi Persada, S.E., } \\
\text { M.M. }\end{array}$ \\
\hline & $21: 15-21: 30$ & Kesimpulan dan penutup & $\begin{array}{l}\text { Bapak Ade Yusuf, S.E., } \\
\text { M.M. }\end{array}$ \\
\hline
\end{tabular}

Berikut gambar foto pelaksanaan pengabdian kepada masyarakat:

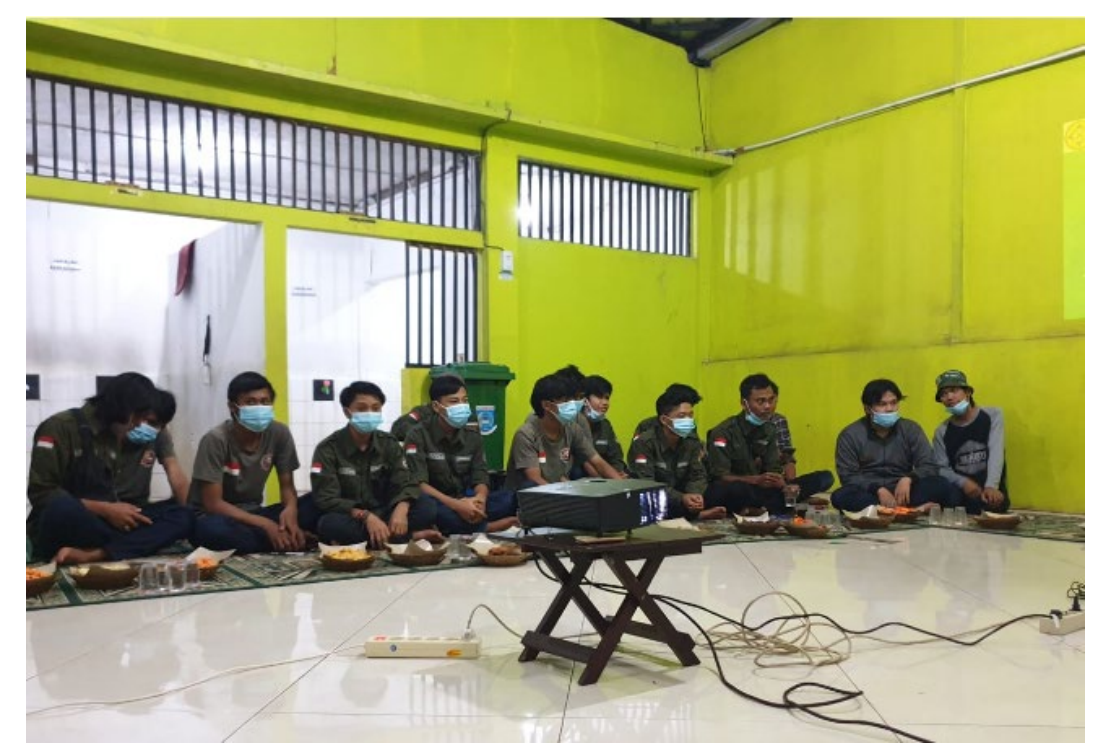

Gambar 2 Anggota Komunitas Arimbin IX 


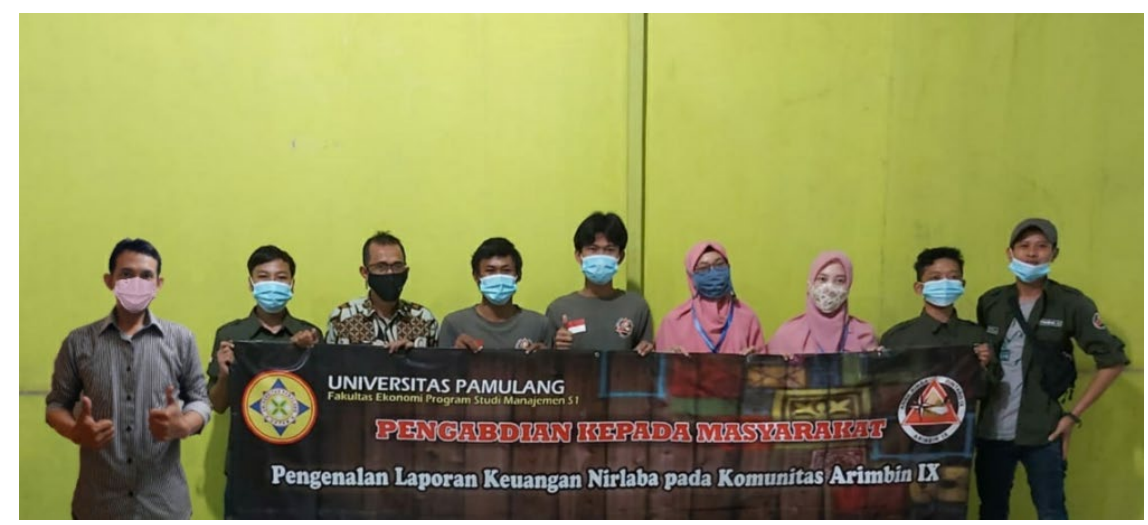

Gambar 3 Foto bersama Tim Pengabdi dan Anggota Komunitas Arimbin IX

\section{KESIMPULAN DAN SARAN}

\section{Simpulan}

Kegiatan pengabdian berjalan dengan lancar. Dari dua sesi pelaksanaan anggota komunitas Arimbin IX sudah memiliki gamabarn dan bisa membuat laporan keuangan untuk komunitasnya. Hal ini dapat diketahui dari diskusi dan pembuatan laporan posisi keuangan.

\section{Saran}

Serupa dapat dilaksanakan kembali dengan berkesinambungan mengadakan pemberdayaan anggota komunitas guna meningkakan knowledge khususnya anggota komunitas Arimbi IX.

\section{Ucapan Terima Kasih}

Acara dapat terselenggara dengan baik, penulis pada kesempatan kali ini inginmengucapkan terimakasih kepada:

1. Bapak Dr. H Dayat Hidayat M.M., selaku Rektor Universitas Pamulang.

2. Bapak Dr. Ali Maddinsyah, S.E., M.M., selaku Ketua LPPM Universitas Pamulang

3. Bapak Dr. Kasmad S.E., M.M., selaku Ketua Prodi S1 Manajemen

4. Bapak Dr. Udin Ahidin, S.E., M.M., selaku Wakil Ketua Prodi S1 Manajemen

5. Bapak Drs. Waluyo Jati, M.M., selaku Sekretaris Prodi S1 Manajemen

6. Bapak Jumadi selaku Tokoh Masyarakat Kelurahan Pondok Pucung

7. Bapak Imbron, S.E., M.M., selaku pembina komunitas Arimbin IX

8. Seluruh anggota komunitas Arimbin IX

\section{DAFTAR PUSTAKA}

Anggraeny, S. N., Kudhori, A., \& Fikria, A. (2018). Pelatihan Penyusunan Laporan Keuangan Dalam Lingkup Yayasan Pendidikan Dan Pondok Pesantren Subulul Huda Kembang Sawit. DIKEMAS (Jurnal Pengabdian Kepada Masyarakat), 2(1).

Ikatan Akuntansi Indonesia. Pernyataan Standar Akuntansi Keuangan (PSAK) 45 Tentang Laporan Keuangan Entitas Nirlaba. P 09-34 (Book).

Sujarweni, V. (2015). Akuntansi Sektor Publik. Pustaka Baru Press. 